Research Paper

\title{
NOMO-1 gene is deleted in early-onset colorectal cancer
}

\author{
José Perea ${ }^{1,2}$, Juan Luis García ${ }^{3}$ Jessica Pérez ${ }^{3}$, Daniel Rueda2,4, María Arriba ${ }^{2}$, \\ Yolanda Rodríguez ${ }^{5}$, Miguel Urioste ${ }^{6,7}$, Rogelio González-Sarmiento $^{3}$ \\ ${ }^{1}$ Surgery Department, University Hospital 12 de Octubre, Madrid, Spain \\ ${ }^{2}$ Digestive Cancer Research Group, 12 de Octubre Research Institute, Madrid, Spain \\ ${ }^{3}$ Department of Medicine, Molecular Medicine Unit, Biomedical Research Institute of Salamanca (IBSAL), Institute of Molecular \\ and Cellular Biology of Cancer (IBMCC), University of Salamanca, SACYL, CSIC, Salamanca, Spain \\ ${ }^{4}$ Molecular Biology Laboratory, University Hospital 12 de Octubre, Madrid, Spain \\ ${ }^{5}$ Pathology Department, University Hospital 12 de Octubre, Madrid, Spain \\ ${ }^{6}$ Familial Cancer Clinical Unit, Spanish National Cancer Centre (CNIO), Madrid, Spain \\ ${ }^{7}$ Center for Biomedical Network Research on Rare Diseases (CIBERER), Institute of Health Carlos III, Madrid, Spain
}

Correspondence to: José Perea, email: josepereag@hotmail.com

Keywords: early-onset colorectal cancer, NOMO-1, nodal pathway, array comparative genomic hybridization, 16p13.12-p13.11

Received: December 09, 2016

Accepted: February 07, 2017

Published: February 18, 2017

Copyright: Perea et al. This is an open-access article distributed under the terms of the Creative Commons Attribution License (CC-BY), which permits unrestricted use, distribution, and reproduction in any medium, provided the original author and source are credited.

\section{ABSTRACT}

To characterize clinical features of a recurrent alteration in 16p13.12-p13.11 in Colorectal Cancer (CRC), mainly in Early-onset subgroup (EOCRC), and to assess the status of NOMO1, a gene located in that region, we analyzed differential clinicopathological, familial and molecular features of CRC subsets with and without alterations in the 16p13.12-p13.11, in global and EOCRC groups. We confirmed the region by fluorescence in-situ hybridization, and Quantitative Real-Time PCR analyzed the status of NOMO1 in different age-of-onset and Microsatellite Instability (MSI)status CRC subsets. Both age-of-onset subsets were subsequently extended to further confirm NOMO1 gene changes. 16p13.12-p13.11 alterations were observed in $23.3 \%$ of CRCs, and was detected more frequently in EOCRC (33.3\%) than in late-onset CRC $(16.3 \%)$. The group with deletion in $16 p$ showed a higher frequency of females and left-colon locations; a better prognosis; and higher Chromosomal Instability. Within the primary EOCRC population, 34 out of 34 of tumours showed a homozygous deletion in NOMO1, while in the late-onset population only 2 of the 17 tumours $(11.7 \%)$ showed it. In the extended group, we found 61 out of 75 EOCRC patients ( $81.3 \%)$ with homozygous deletion and 7 patients $(9.3 \%)$ with heterozygous deletion of NOMO1; moreover, in the new $\mathbf{5 0}$ late-onset patients, the proportions of deletions decreased. Microsatellite-Stable (MSS) EOCRC showed a very high proportion of homozygous loss of NOMO1 ( 54 of 59 cases, $91.5 \%$ ), while the deletion was observed in only 7 out of 16 MSI cases. Deletion of NOMO1 is a molecular marker predominantly associated with EOCRC, particularly MSS subtypes.

\section{INTRODUCTION}

Early-onset Colorectal Cancer (EOCRC) has an incidence of 2-8\% of all Colorectal Cancers (CRCs) and it has increased in the past decades to reach $11 \%$ of colon cancers and $18 \%$ of rectal cancers [1]. The impact of EOCRC on the population is undeniably important, and until recently the idea prevailed that this subset of CRC occurred mainly in hereditary CRC forms. However, recent studies challenge this statement, since they are primarily Microsatellite Stable (MSS) cases [2-6]. Moreover, EOCRC (except cases with an already known hereditary component) may be a specific subgroup of CRC [3-5], so that a deeper understanding of the underlying molecular mechanisms is essential.

EOCRC has evolved from a controversy on its natural history and prognosis to the characterization of an important heterogeneity within this group [6]. Moreover, it has been proposed that age of onset is a major criterion for subclassifying CRC [3]. Most studies conclude that there 
are differential features within this age group not only from a clinical point of view but also, and more significantly, according to a number of differential molecular features: a high degree of LINE-1 hypomethylation [7], more frequent chromosomal and genetic alterations (including some susceptibility variants), underlying an inherited or familiar predisposition [8-10], and unique characteristics, including clinical and molecular features and the type of telomere maintenance mechanism $[4,5]$. In spite of all these differential molecular features, to date there is no known molecular or genetic target associated with EOCRC.

$\mathrm{CRC}$ results from the accumulation of genetic alterations, and somatic copy number alterations (CNAs) play an important role in its development. Genome-wide survey of CNAs provides opportunities for identifying cancer driver genes in an unbiased manner [11]. In an attempt to better characterize EOCRC, we have previously reported results from an array-Comparative Genomic Hybridization (aCGH) study in which we compared early and late-onset CRC [10]. Analysis of the data have revealed a recurrent deletion in chromosome 16p13.12-p13.11, either alone or associated with other changes (Supplementary Figure 1). The aims of our study were to define the possible clinical phenotype of the cases showing this chromosomal alteration as well as to find out genes in this region that could be altered.

\section{RESULTS}

\section{6p deletion is more frequent in EOCRC than in late-onset CRC}

Sixty cases from the EOCRC subset and 86 from the late-onset population were studied by aCGH (the others could not be studied because of lack of material); analysis of the data revealed a recurrent focal deletion in chromosome 16p13.12-p13.11, either as the unique change or associated with other changes (Supplementary Figure 1). This focal alteration was observed in $23.3 \%$ $(34 / 146)$ cases in our series, and was detected more frequently in early-onset CRC $(33.3 \%, 20 / 60)$ than in lateonset CRC $(16.3 \%, 14 / 86)(p=0.028)$ (Figure 1).

In Table 1 we compare clinico-pathological, familial, molecular and follow-up features of the groups according to $16 \mathrm{p}$ status as determined by aCGH. In the global population (without defining any age-of onset criteria), the $16 \mathrm{p}$ deletion appeared to be more frequent in females (58.8\% vs 39.3\%). Moreover, in the group with $16 \mathrm{p}$ deletion we observed a very low rate of rectal $(17.6 \%$ vs $42 \%)$ and a high rate of left-colon locations (47.1\% vs $27.7 \%$ ); a better prognosis, and a higher Chromosomal Instability. Kaplan-Meier curves are shown in Figure 2, confirming the better prognosis of the group with 16p13.12-p13.11 deletion, mainly for OS. When we analysed the EOCRC group separately, only tumor location and Chromosomal Instability (number of CNAs) remained statistically significantly different between the patients with and without $16 \mathrm{p}$ deletion (Table 1 ).

\section{6p13.12-p13.11 deletion causes loss of NOMO1 gene}

Analysis of 16p13.12-p13.11 region by Fluorescence in-situ hybridization analysis (FISH) showed a minimal common region between bases 14738223 and 15353060 with a size of 614838 bp (hg19) (http://genome.ucsc. edu). This region contains the genes BFAR (bifunctional apoptosis regulator), PLA2G10 (phospholipase A2), NPIPA2 (nuclear pore complex interacting protein) $A B C C 6 P 2$ (ATP-binding cassette, sub-family $\mathrm{C}$, member 6 pseudogene 2), NOMO1 (NODAL modulator 1), PDXDC1 (pyridoxal-dependent decarboxylase domain containing 1), NTAN1 (N-terminal asparagine amidase), RRN3 (RRN3 RNA polymerase I transcription factor homolog), and PKD1P6 (polycystic kidney disease 1 (autosomal dominant) pseudogene 6).

We analysed the status of the NOMO1 gene in both age-at-onset subgroups. Within EOCRC, all 20 cases with a cytogenetic 16p13.12-p13.11 deletion showed homozygous deletion of NOMO1. Unexpectedly, we also observed 14 cases without cytogenetic evidence of a 16p13.12-p13.11 deletion that presented also homozygous deletion of NOMO1 (Figure 1). Thus, within the EOCRC population, 34 of 34 studied tumors showed a homozygous deletion in NOMO1 (100\%). Lack of material prevented us to further analyse the remaining cases.

Within late-onset CRC, we were able to study 9 of the 14 cases showing cytogenetic 16p13.12-p13.11 deletion: only two of these cases showed homozygous loss of NOMO1, five showed a heterozygous deletion and the other two showed NOMO1 wild-type (Figure 1). We also studied 8 late-onset $\mathrm{CRC}$ without $16 \mathrm{p}$ deletion, and all of them had NOMO1 wild-type (Figure 1). In summary, only 2 out of 17 late-onset CRCs (11.7\%) showed a homozygous deletion in NOMO1.

To further investigate the high rate of NOMO1 loss observed in the preliminary series of EOCRC (34 out of 34), we increased the number to 75 early-onset cases as mentioned in the Methods section. Results are shown in Table 2. Of the 41 new cases, 27 showed NOMO1 homozygous deletion, 7 showed heterozygous deletion, and 7 showed NOMO1 wild-type. Taken together, from a total of 75 EOCRC cases we found 61 patients $(81.3 \%)$ with a homozygous loss; 7 patients $(9.3 \%)$ with a heterozygous loss; and 7 patients $(9.3 \%)$ without loss of NOMO1. Of the other 50 late-onset CRC added, only one showed NOMO1 homozygous deletion, 4 showed heterozygous deletion, and 45 showed NOMO1 wildtype. Taken together, from a total of 67 late-onset cases, we found 3 patients $(4.5 \%)$ with a homozygous loss; 9 patients $(13.4 \%)$ with a heterozygous loss; and the rest without loss of NOMO1. 
We divided our EOCRC cases according to Microsatellite Instability (MSI) phenotype. MSS-EOCRC showed a very high proportion of homozygous NOMO1 deletion (54 of 59, 91.5\%), while it was present only in 7 of 16 MSI-EOCRC cases (43.74\%). Heterozygous deletion of NOMO1 appears to be rare in MSS-EOCRC $(3.3 \%, 2 / 59)$ and relatively common in MSI-EOCRC cases $(31.2 \%$, $5 / 16$ ) (Differences between MSI groups according to the NOMO1 status in the Global group: $p<0.001)$. Fourteen out of the $16 \mathrm{MSI}$ cases showed germline mutations in the Mismatch Repair (MMR) genes, so that they were defined as Lynch syndrome cases. Only one of the others showed MLH1 gene promoter hypermethylation. These last two, without MMR germline mutation, exhibited homozygous NOMO1 deletion, showing the Lynch syndrome cases all the three possible NOMO1 mutation status.

\section{NOMO1 deletion is somatic}

We analysed NOMO1 in DNA obtained from peripheral blood samples of 13 individuals with EOCRC and homozygous deletion in their tumours. None of these cases showed NOMO1 deletion in their peripheral blood, which strongly suggests that NOMO1 deletion is somatic.

\section{DISCUSSION}

Deletions of $16 \mathrm{p} 13$ observed by aCGH have been associated with multiple congenital anomalies [12]. In cancer, these changes were previously reported in Perivascular Epithelioid Cell tumors (PEComa) and prostate cancer $[13,14]$. A small deletion in chromosome $16 \mathrm{p} 13.2$ affecting the alternative splicing factor $R B F O X 1$ was found at a significantly higher rate in the $C R C$ British Bangladeshi patients (50\%) than in CRC British Caucasians patients (15\%), with the Bangladeshi CRC patients being considerably younger [15]. However, this gene is located at a more telomeric position than the deletion we have pointed out, and we therefore decided to further study the involvement of the $16 \mathrm{p}$ deletion in our series of colorectal tumors. Interestingly, the 16 p13.12-p13.11 region we observed was significantly more frequently deleted in EOCRC than in late-onset CRC and showed some important clinical and prognostic implications. Apart from a better prognosis, we observed the almost complete absence of rectal tumors within the EOCRC subset with $16 \mathrm{p}$ deletion. The predominance of left-colon cancer and a high chromosomal instability in these cases are also remarkable. Different nearby regions
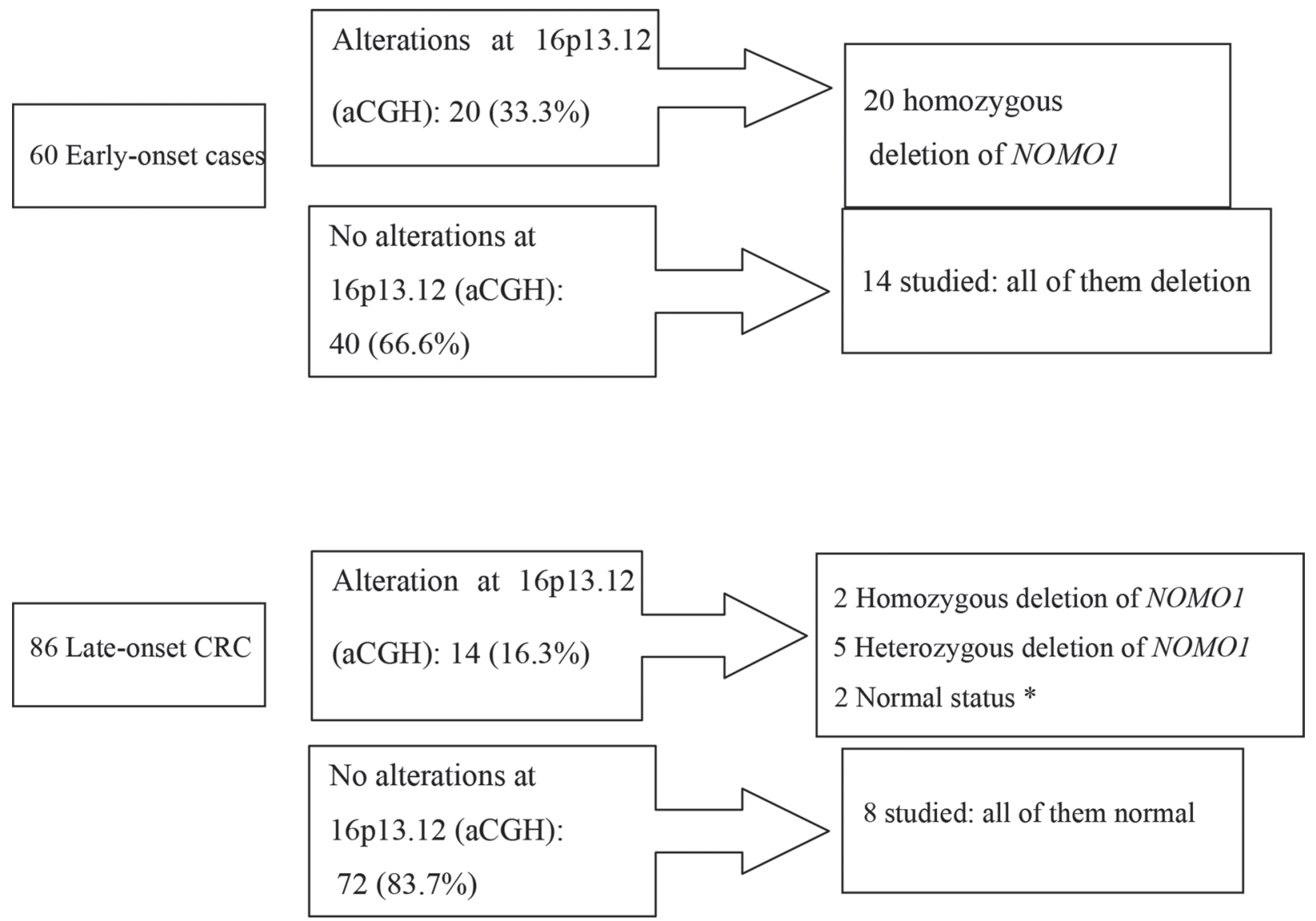

Figure 1: Losses at 16p13.12-p13.11 and NOMO-1 alterations within the early-onset CRC and late-onset CRC subgroups. *Only 9 cases could be analyzed, because of lack of material. 
Table 1: Clinical, pathological and familial features of all CRC cases (global group), and comparison of the subgroups with and without $16 \mathrm{p}$ alterations within the global and the early-onset groups

\begin{tabular}{|c|c|c|c|c|c|c|}
\hline & $\begin{array}{c}\text { 16p altered } \\
\text { Global } \\
n(\%)\end{array}$ & $\begin{array}{l}\text { 16p normal } \\
\text { Global } \\
n(\%)\end{array}$ & $p\left(\chi^{2}\right)$ & $\begin{array}{c}16 \mathrm{p} \text { altered } \\
\text { Early-onset } \\
n(\%)\end{array}$ & $\begin{array}{c}16 p \text { normal } \\
\text { Early-onset } \\
n(\%)\end{array}$ & $p\left(\chi^{2}\right)$ \\
\hline Patients & $34(23.3)$ & $112(76.7)$ & & $20(33.3)$ & $40(66.7)$ & \\
\hline Mean age of onset (SD) ${ }^{1}$ & & & & $38.9(5.6)$ & $39.4(4.9)$ & NS \\
\hline $\begin{array}{l}\text { Sex: } \\
\text { Male } \\
\text { Female } \\
\end{array}$ & $\begin{array}{l}14(41.2) \\
20(58.8)\end{array}$ & $\begin{array}{l}68(60.7) \\
44(39.3)\end{array}$ & 0.05 & $\begin{array}{c}9(45) \\
11(55)\end{array}$ & $\begin{array}{l}27(67.5) \\
13(32.5)\end{array}$ & NS \\
\hline \begin{tabular}{|l|} 
Location: \\
Right colon \\
Left colon \\
Rectum \\
\end{tabular} & $\begin{array}{c}12(35.3) \\
16(47.1) \\
6(17.6)\end{array}$ & $\begin{array}{l}34(30.4) \\
31(27.7) \\
47(42)\end{array}$ & 0.024 & $\begin{array}{c}7(35) \\
13(65) \\
0(0)\end{array}$ & $\begin{array}{c}6(15) \\
15(37.5) \\
19(47.5)\end{array}$ & 0.001 \\
\hline $\begin{array}{l}\text { Tumor differentiation }{ }^{2} \text { : } \\
\text { Poor }\end{array}$ & $2 / 30(6.7)$ & $5 / 99(5.1)$ & NS & $2 / 16(12.5)$ & $1 / 33(3)$ & NS \\
\hline $\begin{array}{l}\text { Mucin production }{ }^{2} \text {. } \\
\text { "Signet ring" cells }{ }^{2} \text {. }\end{array}$ & $\begin{array}{c}6 / 30(20) \\
0(0)\end{array}$ & $\begin{array}{c}23 / 99(23.2) \\
4 / 99(4)\end{array}$ & $\begin{array}{l}\text { NS } \\
\text { NS }\end{array}$ & $\begin{array}{c}5 / 16(31.3) \\
0 / 16(0)\end{array}$ & $\begin{array}{l}9 / 33(27.3) \\
2 / 33(6.1)\end{array}$ & $\begin{array}{l}\text { NS } \\
\text { NS }\end{array}$ \\
\hline $\begin{array}{l}\text { Modified Astler Coller stage: } \\
\text { A } \\
\text { B } \\
\text { C } \\
\text { D }\end{array}$ & $\begin{array}{l}6(17.6) \\
18(52.9) \\
4(11.8) \\
6(17.6)\end{array}$ & $\begin{array}{l}13(11.6) \\
48(42.9) \\
29(25.9) \\
22(19.6)\end{array}$ & NS & $\begin{array}{c}4(20) \\
11(55) \\
1(5) \\
4(20)\end{array}$ & $\begin{array}{l}11(27.5) \\
12(30) \\
9(22.5) \\
8(20)\end{array}$ & NS \\
\hline \begin{tabular}{|l|} 
Associated polyps \\
Mean number of polyps (SD) \\
Type: \\
Addenomatous \\
Hyperplastic \\
Mixed \\
\end{tabular} & $\begin{array}{c}25(73.5) \\
2.3(2.8) \\
\\
11(44) \\
3(22) \\
11(44) \\
\end{array}$ & $\begin{array}{c}66(58.9) \\
2.8(6.3) \\
\\
\\
39(59) \\
9(14) \\
18(27) \\
\end{array}$ & $\begin{array}{l}\text { NS } \\
\text { NS } \\
\text { NS }\end{array}$ & $\begin{array}{l}13(65) \\
2.2(2.6) \\
\\
5(38.5) \\
2(15.4) \\
6(46.1) \\
\end{array}$ & $\begin{array}{l}22(55) \\
2.8(8) \\
\\
9(40.9) \\
5(22.7) \\
8(36.4) \\
\end{array}$ & $\begin{array}{l}\text { NS } \\
\text { NS } \\
\text { NS }\end{array}$ \\
\hline Synchronous o metachronous CRCs. & $4(11.8)$ & $19(17)$ & NS & $3(15)$ & $2(5)$ & NS \\
\hline Recurrence $^{3}$ & $2(7.7)$ & $15(16.7)$ & NS & $2(12.5)$ & $5(15.6)$ & NS \\
\hline Related mortality & $6(17.6)$ & $36(32.1)$ & NS & $3(15)$ & $11(27.5)$ & NS \\
\hline Disease-free survival (SD) $^{1}$ & $55.8(46.4)$ & $32.9(31.9)$ & 0.02 & $65.4(47)$ & $51.7(36.5)$ & 0.2 \\
\hline Overall survival (SD) ${ }^{1}$ & & & 0.15 & $72(42.8)$ & $61.1(29.8)$ & 0.3 \\
\hline MSI & $4(11.8)$ & $12(10.7)$ & NS & $3(15)$ & $6(15)$ & NS \\
\hline MMR genes mutations & $3(8.8)$ & $5(4.5)$ & NS & $3(15)$ & $4(10)$ & NS \\
\hline CIMP-High & $9(26.5)$ & $22(19.6)$ & NS & $6(30)$ & $6(15)$ & 0.1 \\
\hline CNA (SD) $)^{1}$ & $175(90.5)$ & $110(75.5)$ & 0.01 & $160(128.5)$ & $63.7(67.3)$ & 0.004 \\
\hline $\begin{array}{l}\text { Familial history of cancer } \\
\text { Amsterdam II Positive families. } \\
\text { Aggregation for Lynch neoplasm. } \\
\text { Aggregation for Lynch unrelated neoplasm. } \\
\text { Sporadic cases. } \\
\end{array}$ & $\begin{array}{l}4(11.8) \\
13(38.2) \\
8(23.5) \\
17(50)\end{array}$ & $\begin{array}{l}7(6.3) \\
27(24.1) \\
22(19.6) \\
75(67)\end{array}$ & NS & $\begin{array}{c}4(20) \\
10(50) \\
8(40) \\
32(46,4)\end{array}$ & $\begin{array}{c}7(17.5) \\
19(47.5) \\
14(36) \\
17(42.5)\end{array}$ & NS \\
\hline
\end{tabular}

${ }^{1}$ Statistical analysis was carried out using Student's $t$ test. ${ }^{2}$ Percentages shown are based on varying total numbers as some cases were excluded because only one biopsy was taken (stage D), or because tumours were severely dysplastic with "in situ" carcinoma, and it was not possible to study any other characteristic. ${ }^{3}$ Cases showing recurrence are those with stage C or less at diagnosis.

SD: Standard Deviation. NS: Not significant. CRC: Colorectal Cancer CIMP: CpG Island Methylator Phenotype. MSI: Microsatellite instability. MMR: Mismatch Repair system. CNA: Copy Number Alterations per case.
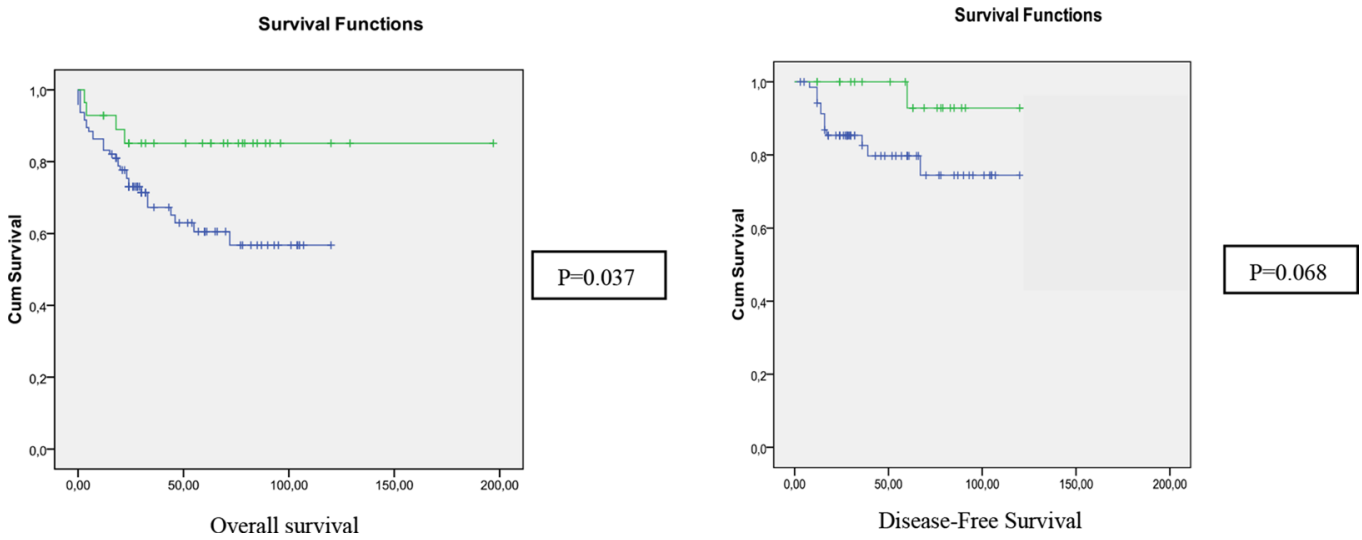

Figure 2: Kaplan-meier curves for overall survival and disease-free survival of the global subset, according to the status of 16p13.12 in aCGH (Green: altered; Blue: normal). 
Table 2: Alterations in NOMO1 in early-onset CRC in the primary group, the subset extension group, and the global CRC group

\begin{tabular}{|c|c|c|c|c|c|c|}
\hline & \multicolumn{2}{|c|}{ Primary group } & \multicolumn{2}{|c|}{ Subset extension group } & \multicolumn{2}{|c|}{ GLOBAL } \\
\hline & $\begin{array}{l}\text { MSS } \\
n(\%)\end{array}$ & $\begin{array}{c}\text { MSI } \\
n(\%)\end{array}$ & $\begin{array}{l}\text { MSS } \\
n(\%)\end{array}$ & $\begin{array}{l}\text { MSI } \\
n(\%)\end{array}$ & $\begin{array}{l}\text { MSS } \\
n(\%)\end{array}$ & $\begin{array}{c}\text { MSI } \\
n(\%)\end{array}$ \\
\hline $\begin{array}{l}\text { NOMO1 } \\
\text { Homozygous deletion }\end{array}$ & $31(100)$ & $3(100)$ & $23(82)$ & $4(31)$ & $54(92)$ & $7(44)$ \\
\hline $\begin{array}{l}\text { NOMO1 } \\
\text { Heterozygous deletion }\end{array}$ & 0 & 0 & $2(7)$ & $5(38)$ & $2(3)$ & $5(31)$ \\
\hline NOMO1 Normal & 0 & 0 & $3(11)$ & $4(31)$ & $3(5)$ & $4(25)$ \\
\hline
\end{tabular}

Primary group: Preliminary series of early-onset CRC, from the aCGH study. Subset extension group: Expansion of the series with Early-onset CRC patients from three different institutions, in order to confirm the preliminary results. GLOBAL: The sum of the two previous. Differences between MSI groups according to the NOMO1 status in the Global group: $p<0.001$. MSI: Microsatellite Instability. MSS: Microsatellite Stability. Ratios are calculated for subgroups of MSI-status.

have been related with prognostic aspects. For example, losses at the 16p13.3 region have been described to lead to poor prognosis in CRC; this region bears a total of 167 known genes among which the tumor suppressor gene AXIN1 [11, 16]. The apparent contradiction between better prognosis and high chromosomal instability of cases with $16 p$ deletion observed in the present study should be explained by of the greater proportion of Microsatellite And Chromosomal Stable tumours within EOCRC, which are the ones showing a worse prognosis in this particular subset of CRC.

One of the genes located in 16p13.12-p13.11 is NOMO1. Unexpectedly, we found NOMOI deletion not only in cases with cytogenetic deletion in 16p, mainly in the EOCRC, but also in most early-onset cases without $16 p$ deletion (34 out of 34 EOCRC cases studied by aCGH and FISH), while it barely reached $12 \%$ in the late-onset CRC subset. The identification of deletions of NOMO1 gene detected by qRT-PCR highlight the role of this gene in colorectal carcinogenesis, especially in earlyonset tumors. However, to date there is no evidence that NOMO1 is related with carcinogenesis. Its main function currently known is to form part of a protein complex that antagonizes Nodal signaling, a pathway essential for patterning of the early embryo during mesoderm and endoderm induction as well as for the specification of leftright asymmetry [17]. According to the Cancer Gnome Atlas data alterations involving 16p13 appears to have a limited role in CRC that is confirmed in our analysis of other tumours [18].

When we extended the analysis, we confirmed the important proportion or EOCRC cases showing NOMOI loss, and preliminary findings also indicate that this loss is specific of CRC and, more significantly, that it appears to be an important clinical marker of MSS EOCRC as we observed the deletion in more than $90 \%$ of the cases. Its possible carcinogenetic role remains uncertain but there is recent evidence supporting the possibility that $\mathrm{NOMOI}$ could act as a tumor suppressor gene: Nodal pathway activity is upregulated in human cancers such as malignant melanoma [19]; the upregulation of Cripto-1, a protein involved downstream of Nodal signaling is observed in many epithelial cancers like CRC [20], and Cripto-1 overexpression promotes tumorigenesis in xenografts and transgenic mice [21]. Moreover, collectively, Nodal signaling pathway promotes the self-renewal of human Colon Cancer Stem cells and mediates carcinogenesis of human CRC in an autocrine manner through Smad2/3 pathway [22]. As Nomol antagonizes the Nodal signaling pathway [23], the deletion of NOMOI could lead in a downregulation of the protein and consequently, an upregulation of the Nodal signaling pathway.

In summary, apart from the clinical value of loss of 16p13.12-p13.11, we identify loss of NOMO1 as a molecular marker mainly associated with EOCRC, and particularly with MSS subtypes. Our findings may serve as a starting point for further studies to confirm the potential carcinogenetic value of this deletion, which would place NOMO1 in a suitable position as a potential therapeutic target for EOCRC treatment.

\section{MATERIALS AND METHODS}

\section{Families, samples and data collection}

A total of 82 consecutive individuals with CRC diagnosed at an age of 45 years or younger were collected from our institution. We also collected 97 consecutive individuals who were diagnosed during the same period with CRC but at an age of 70 years or older, to compare with the EOCRC group. These groups have been described previously $[4,10]$. We collected clinicopathological data and analyzed MSI status, the mutational state of MMR genes, and the $\mathrm{CpG}$ methylation phenotype of all cases. Follow-up was at least 5 years from surgery, and Disease-Free Survival (DFS) and Overall Survival (OS), 
recurrence and cancer-related death for each case were determined. Details of these studies have been previously reported $[4,10]$.

In order to confirm our findings, we expanded our series with EOCRC patients from three different institutions (University Hospital of Salamanca, Familial Cancer Clinical Unit of the Spanish National Cancer Research Centre, and 12 de Octubre University Hospital) obtaining 41 additional cases. The main clinical features of these patients were also recorded. We collected as well another 50 late-onset CRC from University Hospital of Salamanca, all of them showing MSS.

\section{Chromosomal instability: array comparative genomic hybridization (aCGH)}

Sixty early-onset CRC cases and 86 late-onset CRCs were studied by array-CGH using oligonucleotide microarrays (Roche NimbelGen, Inc., Reykjavik, Iceland) in order to indentify CNAs as previously reported (10). Each genomic region exhibiting a copy number change was examined using the UCSC genome browser (http://genome.ucsc.edu/) to determine the location and significance of the change.

\section{Fluorescence in-situ hybridization analysis (FISH)}

To confirm the gains and losses detected by arrayCGH, FISH analysis was performed using BAC clones 354N7 mapped to 16q22.1 (bases 68,727,161-68,887,391) and CTD 2504F3 mapped to 16p13.1 (bases 15,982,491$16,190,907)$, as previously described (NCBI16/hg18) [24]. These clones were selected from the same BAC clone library used for the BAC-array studies (Wellcome Trust Sanger Institute, Cambridge, UK). DNA from the BAC clones was isolated and directly labelled with either Spectrum Green-dUTP or Spectrum Orange-dUTP (Vysis, Downers Grove, IL), by nick translation and hybridized as previously described [24]. All BAC clones were first hybridized to normal human metaphase chromosomes in order to verify their location.

Paraffin-embedded tissue sections (4- $\mu \mathrm{m}$ thick) were deparaffinized, dehydrated and air-dried. The slides were placed in $2 \mathrm{mM}$ EDTA ( $\mathrm{pH}$ 9) for 15 minutes. After cooling, the slides were transferred to a Coplin jar containing $40 \mathrm{ml}$ of $0.9 \% \mathrm{NaCl}(\mathrm{pH} 1.5)$ and $160 \mathrm{mg}$ of pepsin (Sigma) preheated to $37^{\circ} \mathrm{C}$. Following incubation for 15 minutes, the sections were dehydrated in an alcohol series and fixed in 3:1 methanol:acetic acid for 10 minutes. The slides were then incubated in a Hybrite hybridization chamber (Vysis) for 12 minutes at $72^{\circ} \mathrm{C}$, followed by 15 to 20 hours at $37^{\circ} \mathrm{C}$. After hybridization, the slides were washed in standard solutions of saline citrate. Nuclei were counterstained with DAPI (Vector Laboratories Inc.). The images were captured with an Olympus BX60 epifluorescence microscope coupled to a CCD camera and evaluated with Cytovision software (Applied Imaging). Approximately 400 non-overlapping tumor cells were evaluated (Supplementary Figure 2).

\section{Quantitative real-time PCR}

For real-time quantification of target gene expression, one-step real-time Polymerase Chain Reaction (RT-PCR) was performed using FastStart Universal SYBR Green Master (ROX) in a StepOnePlus ${ }^{\mathrm{TM}}$ Real-Time PCR System (Life Technologies-Invitrogen, California, U.S.A.). A fragment of the NOMO1 gene was amplified from the DNA of patients and controls using the following primers: $F$ : 5'-agctccatgtggatggagtc-3' and R: 5 '-acggatgaagtacagagttc-3. As internal control, the $36 \mathrm{~b} 4$ gene was amplified from the same DNA using the primers: F: 5'-cagcaagtgggaaggtgtaatcc-3' and R: 5'-cccattctatcatcaacgggtacaa-3.

Ten $\mu \mathrm{l}$ RT-PCR of a mix containing $15 \mathrm{ng}$ of total DNA, $1 \mu$ l of the primer dilution, $4 \mu$ l FastStart Universal SYBR Green Master and $4 \mu \mathrm{H}_{2} \mathrm{O}$ were used for amplification. One-step RT-PCR reactions were carried out in 96-well optical reaction plates, covered with MicroAmp ${ }^{\circledR}$ Optical Adhesive Film (Life TechnologiesInvitrogen, California, U.S.A). Cycling was as follows: 10 minutes at $95^{\circ} \mathrm{C}$ followed by 40 cycles of $95^{\circ} \mathrm{C}$ for 15 seconds, $58^{\circ} \mathrm{C}$ for 45 seconds and $72^{\circ} \mathrm{C}$ for 15 seconds. RQ Manager software was used to analyse the values.

The comparative $\mathrm{Ct}$ method $\left(2^{-\Delta \Delta \mathrm{Ct}}\right)$ was used to calculate the relative expression levels of each amplicon. RT-PCR specificity of each PCR reaction was verified by melting curve analysis.

\section{Statistical analyses}

Continuous variables were expressed as mean values plus/minus standard deviation (SD), and categorical variables were expressed as number of cases and their percentage. Differences were considered significant when $p<0.05$. For associations between discrete variables, statistical analyses were performed using Pearson's Chi Square $\left(\chi^{2}\right)$ Test for parametric variables, and Fisher's Exact Test for non-parametric variables. For continuous variables, Student's $t$ test was used. The SPSS v.11.5 for Windows (SPSS, Inc., Chicago, IL) statistical package was used. The Kaplan-Meier method was used to describe the distribution of survival time, and the log-rank test was applied. For analyses of colorectal cancer-specific mortality, death as a result of CRC was the primary end point, and deaths from other causes were censored. The same analysis was carried out for disease-free survival time, using recurrence as the primary endpoint. For aCGH analysis, statistics were as published before [10].

\section{Abbreviations}

aCGH: array-Comparative Genomic Hybridization. CNAs: Copy Number Alterations. CRC: Colorectal 
Cancer. DFS: Disease-Free Survival. EOCRC: Earlyonset Colorectal Cancer. FISH: Fluorescence in-situ hybridization. MMR genes: Mismatch Repair genes. MSI: Microsatellite Instability. MSS: Microsatellite StabilityMicrosatellite Stable. PCR: Polymerase Chain Reaction. SD: Standard Deviation.

\section{ACKNOWLEDGMENTS}

We thank the Tumor Registry of the Pathology Department of the 12 de Octubre University Hospital, the Pathology Department of the University Hospital of Salamanca, and the Tumor Bank of the Spanish National Cancer Research Centre, for providing us with paraffinembedded tissues, and Ron Hartong for his help with the English revision of this article.

\section{CONFLICTS OF INTEREST} interests.

The authors declare that they have no competing

\section{GRANT SUPPORT}

This work was funded by Projects PI10/0683, PI13/01741, PI13/0127, PI16/01920 and PI16/01650, from the Spanish Ministry of Health and Consumer Affairs and FEDER, and was approved by the Ethics Committee of our Institution.

\section{Authors' contributions}

Conception and design: José Perea, Juan L. García, Miguel Urioste, Rogelio González-Sarmiento. Provision of study materials or patients: José Perea, Jessica Pérez, Daniel Rueda, María Arriba, Yolanda Rodríguez, Miguel Urioste, Rogelio González-Sarmiento. Collection and assembly of data: José Perea, Juan L. García, Jessica Pérez, Rogelio González-Sarmiento. Data analysis and interpretation: José Perea, Juan L. García, Rogelio González-Sarmiento. Manuscript writing: José Perea, Juan L. García, Miguel Urioste, Rogelio González-Sarmiento. Final approval of manuscript: All authors.

\section{REFERENCES}

1. Ahnen DJ, Wade SW, Jones WF, Sifri R, MendozaSilveiras J, Greenamyer J, Guiffre S, Axilbund J, Spiegel A, You YN. The increasing incidende of young-onset colorectal cancer: A call to action. Mayo Clinic Proceedings. 2014.

2. Perea J, Álvaro E, Rodríguez Y, Rivera B, Sánchez E, Carbonell P, Mercadillo F, Grávalos C, GonzálezSarmiento R, Hidalgo M, Urioste M. Approach to the early-onset colorectal cancer: Clinicopathological, familial, molecular and immunohistochemical characteristics. World J Gastreoenterol. 2010; 16:3697-3703.
3. Perea J, Rueda D, Canal A, Rodríguez Y, Álvaro E, Osorio I, Alegre C, Rivera B, Martínez J, Benítez J, Urioste M. Age at onset should be a major criterion for subclassification Colorectal Cancer. J Mol Diagn. 2014; 16:116-26.

4. Boardman LA, Johnson RA, Viker KB, Hafner KA, Jenkins RB, Riegert-Johnson DL, Smyrk TC, Litzelman K, Seo S, Gangnon RE, Engelman CD, Rider DN, Vanderboom RJ, et al. Correlation of chromosomal instability, telomere length and telomere maintenance in Microsatellite stable rectal cancer: A molecular subclass of rectal cancer. PLoS ONE. 8:e80015. doi: 10.1371/journal.pone.0080015.

5. Kirzin S, Marisa L, Guimbaud R, De Reynies A, Legrain M, Laurent-Puig $\mathrm{P}$, Cordelier $\mathrm{P}$, Pradère B, Bonnet D, Meggetto F, Portier G, Brousset P, Selves J, et al. Sporadic Early-onset colorectal cancer is a specific subtype of cancer: a morphological, molecular and genetics study. PLoS ONE. 9:e103159. doi:10.1371/journal.pone.0103159.

6. Losi L, Di Gregorio C, Pedroni M, Ponti G, Roncucci L, Scarselli A, Genuardi M, Baglioni S, Marino M, Rossi G, Benatti P, Maffei S, Menigatti M, et al. Molecular genetic alterations and clinical features in early-onset colorectal carcinomas and their role for the recognition of hereditary cancer syndromes. Am J Gastroenterol. 2005; 100:2280-2287.

7. Antelo M, Balaguer F, Shia J, Shen Y, Hur K, Moreira L, Cuatrecasas M, Bujanda L, Giraldez MD, Takahashi M, Cabanne A, Barugel ME, Arnold M, et al. A high degree of LINE-1 hypomethylation is a unique feature of early-onset colorectal cancer. PLoS One. 2012; 7:e45357. doi: 10.1371/ journal.pone.0045357.

8. Giráldez MD, López-Dóriga A, Bujanda L, Abulí A, Bessa X, Fernández-Rozadilla C, Muñoz J, Cuatrecasas M, Jover R, Xicola RM, Llor X, Piqué JM, Carracedo A, et al. Susceptibility genetic variants associated with early-onset colorectal cancer. Carcinogenesis. 2012; 33:613-19.

9. Giráldez MD, Balaguer F, Bujanda L, Cuatrecasas M, Muñoz J, Alonso-Espinaco V, Larzabal M, Petit A, Gonzalo V, Ocaña T, Moreira L, Enríquez-Navascués JM, Boland CR, et al. MSH6 and MUTYH deficiency is a frequent event in early-onset colorectal cancer. Clin Cancer Res. 2010; 16:5402-13.

10. Arriba M, García JL, Inglada-Pérez L, Rueda D, Osorio I, Rodríguez Y, Álvaro E, Sánchez R, Fernández T, Pérez J, Hernández JM, Benítez J, González-Sarmiento R, et al. DNA copy number profiling reveals different patterns of chromosomal instability within colorectal cancer according to the age of onset. Mol Carcinog. 2016; 55:705-16.

11. Wang H, Liang L, Fang JY, Xu J. Somatic gene copy number alterations in colorectal cancer: new quest for cancer drivers and biomarkers. Oncogene. 2016; 35:2011-9.

12. Nagamani SC, Erez A, Bader P, Lalani SR, Scott DA, Scaglia F, Plon SE, Tsai CH, Reimschisel T, Roeder E, Malphrus AD, Eng PA, Hixson PM, et al. Phenotypic manifestations of copy number variation in chromosome 16p13.11. Eur J Hum Genet. 2011; 19:280-6. 
13. Pan CC1, Chung MY, Ng KF, Liu CY, Wang JS, Chai CY, Huang SH, Chen PC, Ho DM. Constant allelic alteration on chromosome 16p (TSC2 gene) in perivascular epithelioid cell tumour (PEComa): genetic evidence for the relationship of PEComa with angiomyolipoma. J Pathol. 2008; 214:387-393.

14. Choucair KA, Guérard KP, Ejdelman J, Chevalier S, Yoshimoto M, Scarlata E, Fazli L, Sircar K, Squire JA, Brimo F, Cunha IW, Aprikian A, Gleave M, et al. The 16p13.3 (PDPK1) Genomic Gain in Prostate Cancer: A Potential Role in Disease Progression. Transl Oncol. 2012; 5:453-60.

15. Sengupta N, Yau C, Sakthianandeswaren A, Mouradov D, Gibbs P, Suraweera N, Cazier JB, Polanco-Echeverry G, Ghosh A, Thaha M, Ahmed S, Feakins R, Propper D, et al. Analysis of colorectal cancers in British Bangladeshi identifies early onset, frequent mucinous histotype and a high prevalence of RBFOX1 deletion. Mol Cancer. 2013; $12: 1$.

16. Kurashina K, Yamashita Y, Ueno T, Koinuma K, Ohashi J, Horie H, Miyakura Y, Hamada T, Haruta H, Hatanaka H, Soda M, Choi YL, Takada S, et al. Chromosome copy number analysis in screening for prognosis-related genomic regions in colorectal carcinoma. Cancer Sci. 2008; 99:1835-1840.

17. Schier AF. Nodal signaling in vertebrate development. Annu Rev Cell Dev Biol. 2003; 19:589-621.

18. Cancer Genome Atlas Network. Comprehensive molecular characterization of human colon and rectal cancer. Nature. 2012; 487:330-7.
19. Topczewska JM, Postovit LM, Margaryan NV, Sam A, Hess AR, Wheaton WW, Nickoloff BJ, Topczewski J, Hendrix MJ. Embryonic and tumorigenic pathways converge via Nodal signaling: role in melanoma aggressiveness. Nat Med. 2006; 12:925-932.

20. Strizzi L, Bianco C, Normanno N, Salomon D. Cripto-1: a multifunctional modulator during embryogenesis and oncogenesis. Oncogene. 2005; 24:5731-5741.

21. Sun Y, Strizzi L, Raafat A, Hirota M, Bianco C, Feigenbaum L, Kenney N, Wechselberger C, Callahan R, Salomon DS. Overexpression of human Cripto-1 in transgenic mice delays mammary gland development and differentiation and induces mammary tumorigenesis. Am J Pathol. 2005; 167:585-597.

22. Gong Y, Guo Y, Hai Y, Yang H, Liu Y, Yang S, Zhang Z, Ma M, Liu L, Li Z, He Z. Nodal promotes the self-renewal of human colon cancer stem cells via an autocrine manner through Smad2/3 signalling pathway. Biomed Res Int. 2014; 2014:364134.

23. Haffner C, Frauli M, Topp S, Irmler M, Hofmann K, Regula JT, Bally-Cuif L, Haass C. Nicalin and its binding partner Nomo are novel Nodal signalling antagonists. EMBO J. 2004; 23:3041-50.

24. Gonzalez MB, Hernandez JM, Garcia JL, Lumbreras E, Castellanos M, Hernández JM, Fernández-Calvo J, Gutiérrez NC, San Miguel JF. The value of fluorescence in situ hybridization for the detection of $11 \mathrm{q}$ in multiple myeloma. Haematologica. 2004; 89:1213-1218. 